\title{
SIMULAÇÃO BASEADA EM DINÂMICA DE SISTEMAS: AVALIAÇÃO DE CENÁRIOS EM UMA ASSOCIAÇÃO DE RECICLAGEM
}

\section{SIMULATION BASED ON DYNAMIC SYSTEMS: SCENARIO EVALUATION IN A RECYCLING ASSOCIATION}

Recebido em: 27 abr. 2020

Aprovado em: 24 jul. 2020

Versão do autor aceita publicada online: 24 jul. 2020

Publicado online: 25 jun. 2021

\section{Como citar esse artigo - American Psychological Association (APA):}

Junges, V. de C., Romio, A. M., Simonetto, E. de O., Campos, S. A. P., \& Bobsin, D. (2022, abr./jun.). Simulação baseada em dinâmica de sistemas: avaliação de cenários em uma associação de reciclagem. Exacta. 20(2), 252-270. https://doi.org/10.5585/exactaep.2021.17058.

Submeta seu artigo para este periódico 7

Dados Crossmark 


\title{
SIMULAÇÃO BASEADA EM DINÂMICA DE SISTEMAS: AVALIAÇÃO DE CENÁRIOS EM UMA ASSOCIAÇÃO DE RECICLAGEM
}

\author{
SIMULATION BASED ON DYNAMIC SYSTEMS: SCENARIO EVALUATION IN A \\ RECYCLING ASSOCIATION
}

\author{
iD Vanessa de Campos Junges ${ }^{1}$ \\ iD Alexsandra Matos Romio ${ }^{2}$ \\ iD Eugênio de Oliveira Simonetto ${ }^{3}$ \\ iD Simone Alves Pacheco de Campos ${ }^{4}$ \\ Debora Bobsin ${ }^{5}$
}

Resumo: O presente artigo teve como objetivo desenvolver e avaliar um modelo de simulação computacional. Esse modelo permite aos trabalhadores da associação Recicla avaliar e analisar cenários acerca da influência da quantidade de pessoas, bem como o impacto no lucro individual e coletivo dos materiais reciclados. Para tanto, foi realizada uma implementação computacional, utilizando o simulador Vensim da área de System Dynamics, em que foram realizados testes, verificando a validação do modelo através da simulação experimental de quatro cenários. Com base nos cenários, identificou-se que é possível estabelecer um ponto de equilíbrio entre a quantidade de resíduos sólidos urbanos coletados pela associação e a quantidade de recicladores trabalhando. Entretanto, para se obter os melhores cenários simulados são necessárias campanhas de coleta seletiva massivas e predição de mão de obra, para se obter maior produtividade de reciclagem coletiva e lucratividade individual.

Palavras-chave: Economia solidária. Reciclagem. Resíduos sólidos urbanos. Simulação computacional. Sistemas dinâmicos.

Abstract: This article aimed to develop and evaluate a computer simulation model. This model allows the workers of the Recicla association to evaluate and analyze scenarios about the influence of the number of people, as well as the impact on the individual and collective profit of recycled materials. For this, a computational implementation was performed, using the Vensim simulator from the System Dynamics area, in which tests were carried out, verifying the validation of the model through the experimental simulation of four scenarios. Based on the scenarios, it was identified that it is possible to establish a balance between the amount of solid urban waste collected by the association and the amount of recyclers working. However, to obtain the best simulated scenarios, massive selective collection campaigns and labor prediction are necessary to obtain greater collective recycling productivity and individual profitability.

Keywords: Solidarity economy. Recycling. Urban solid waste. Computational simulation. System dynamics. 


\section{Introdução}

Ao longo do tempo foi possível perceber a constante e rápida transformação do ambiente, seja em relação ao viés social, ambiental, econômico, político e/ou cultural. Neste meio, o capitalismo passou a se fortalecer, aumentando então, a separação dos indivíduos em classes sociais, ampliando as desigualdades, isto é, gerando aumento do desemprego e exclusão social (Souza, Sauer, \& Benini, 2019). Aliado a isso, os indivíduos passaram a criar novas formas de se realocar no mercado de trabalho, em que uma destas é entendida enquanto economia solidária (Coelho et al., 2016; Souza et al., 2019).

De acordo com o site da Unisol - Centro de Cooperativas e Empreendimentos Solidários, a economia solidária corresponde a 8\% do PIB brasileiro, reunindo 20 mil cooperativas de trabalhadores, sendo empreendimentos de reciclagem, artesãos, agricultura familiar, entre outros. Isto posto, uma das formas de se trabalhar a economia solidária é sob a reciclagem, em que se desenvolvem associações ou cooperativas. Tais espaços surgem como resposta tanto ao desemprego quanto ao meio ambiente, pois os indivíduos passam a tratar de forma correta resíduos que seriam destinados enquanto lixo, agravando o contexto global de poluição (Fidelis, Ferreira, \& Colmenero, 2015; Silva, 2017; Virgolin, Araújo, \& Silva, 2015). Neste meio, Fidelis et al. (2015) e Tiew et al. (2019) destacam sobre a dificuldade que países em desenvolvimento possuem em realizar o processo correto de reciclagem de tais materiais.

Corroborando a este argumento, Silva (2017) salienta que a gestão dos resíduos sólidos urbanos (RSU) se tornou um problema para os municípios, posto que, normalmente o tratamento é incorreto e não possuem uma forma alternativa. Desta forma, é neste cenário que emerge o relevante papel desempenhado pelos recicladores. Fidelis et al. (2015) expõem que os indivíduos que se encontram em tais espaços conseguem fortalecer seu progresso social, bem como contribuem de forma ativa com a sociedade. Ademais, Tiew et al. (2019) apontam que para que estes empreendimentos de reciclagem evoluam, é necessário o apoio e interesse da comunidade.

Nesta perspectiva, ressalta-se que reside uma situação problemática, porque a falta da conscientização da comunidade afeta diretamente o trabalho de tais indivíduos, os quais dependem dos resíduos para sustentarem-se. Camardelo, Oliveira e Stedile (2015) refletem sobre o contexto de dificuldade vivenciado pelos recicladores que acabam optando por trabalhar individualmente, devido assim obterem maior lucro. Enquanto, por outro lado, Silva (2017) e Virgolin, Silva e Araújo (2015) atentam para a relevância de os recicladores unirem-se em associações ou cooperativas, buscando maior valorização do trabalho como um todo.

Sob este entendimento, emerge a necessidade de se pensar sobre a importância de políticas públicas voltadas a associações e cooperativas de reciclagem, enquanto meio de haver maior reconhecimento e auxílio da comunidade em tais ambientes. Há dez anos atrás, isto já era tema de 
reflexão, pois Dagnino e Dagnino (2010) apontam em seu estudo a necessidade de políticas públicas que busquem atuar frente a comunidade como um todo, isto é, trabalhar a cultura, minimizando o descarte inadequado, fortalecendo a compreensão da relevância do trabalho desenvolvido, bem como diminuindo a força do atravessador.

Com base no exposto, o objeto de estudo do presente artigo reside na associação Recicla, a qual está localizada em uma cidade da região noroeste do estado do Rio Grande do Sul. A associação foi escolhida, dentre outras três, devido apresentar maior crescimento mesmo sendo a mais nova, construída em 2009, mas realmente em funcionamento a partir de 2013; bem como possuir interesse em criar formas diferenciadas de arrecadar resíduos.

À vista disso, a questão que norteia este estudo é: qual é o cenário que apresenta melhor quantidade de pessoas e maior desenvolvimento do lucro da associação Recicla? Dessa forma, o objetivo do presente artigo é desenvolver e avaliar um modelo de simulação computacional na associação Recicla. Salienta-se que para o desenvolvimento do modelo computacional foram utilizadas técnicas oriundas da área de System Dynamics (Daellenbach \& Mcnickle, 2005; Gharajedaghi, 2006). Justifica-se a relevância da pesquisa devido o interesse em gerar estimativas de maior ganho aos recicladores a respeito da quantidade de pessoas, bem como o impacto no lucro individual e coletivo.

Além disso, o modelo do estudo visa auxiliar os recicladores da Recicla no processo de decisão entre permanecer na associação atuando na operação de separação e organização dos RSU que são enviados para a reciclagem, ou sair da associação para arrecadar um número maior de resíduos. Esta decisão auxilia a Recicla no planejamento de gestão de pessoas, analisando como irão atuar operacionalmente; bem como considerando a comunidade em relação a ampliação da coleta seletiva envolvida nesse processo.

Para tanto, o artigo está organizado da seguinte forma: na seção 2, é apresentada a base teórica acerca da economia solidária, com direcionamento à reciclagem. O método é detalhado na seção 3. Na seção 4, o modelo é formulado e proposto, enquanto, na seção 5 são apresentados os dados relativos à etapa de validação do sistema e os resultados obtidos. Por fim, na seção 6 são apresentadas as considerações finais do artigo.

\section{Economia solidária sob o viés da reciclagem}

A economia solidária emergiu enquanto uma forma de solução a indivíduos que se encontravam fora do mercado de trabalho, seja por motivo de desemprego ou mesmo a questão de exclusão social (Benini \& Benini, 2015). Conforme Borges e De Souza (2020), pode ser compreendida ainda enquanto uma forma de superação da vulnerabilidade, através de maior participação social e econômica. Atualmente, tal cenário não se transformou, o que se modificou foi a economia solidária, pois passou a 
ter maior respaldo e atrair diversos indivíduos. À vista disso, compreende-se a mesma enquanto um modo de organização coletiva de indivíduos que se unem em cooperativas, associações, empresas de autogestão, isto é, de diversas formas através de trabalho associado (Benini \& Benini, 2015; Borges \& De Souza, 2020).

De acordo com França-Filho (2007), a economia solidária se desenvolve através de iniciativas associativas ou cooperativas voltadas a atividades socioeconômicas, as quais buscam sanar problemas públicos bem delimitados, direcionados a condição de vida dos indivíduos. Torres et al. (2015) complementam que é um modelo econômico, focado no humano, que busca por meio do trabalho cooperado resgatar a autonomia dos envolvidos, através dos princípios de cooperação, autogestão e divisão coletiva dos resultados. Desta forma, trata-se da união de atividades que favorecem a igualdade dos indivíduos, promovendo compromisso coletivo, com base em modos de gestão diversificados (Silva, 2017). Ainda nesta perspectiva, Borges e De Souza (2020, p. 469) argumentam que os indivíduos agem com base na "participação equitativa e democrática, na cooperação de ideias e ideais e na construção coletiva do ambiente de trabalho".

Visto isso, entende-se que surge um novo formato de trabalho, o qual é contrário aos valores considerados no sistema hegemônico, principalmente quando se reflete sobre o individualismo e competitividade, posto que, o pressuposto que reside é o da lógica de inclusão e coletividade (Torres et al., 2015). Souza, Paula e De Souza-Pinto (2012) argumentam sobre a economia solidária voltada a reciclagem, destacando que se tornou uma oportunidade a indivíduos que se encontram afastados do mercado de trabalho. Logo, trata-se de reutilizar e dar o destino correto aos resíduos e, ao mesmo tempo, gerar trabalho e renda.

Aliado a este contexto, organizações voltadas à reciclagem têm surgido no viés de empreendimentos sociais baseados na economia solidária e nos princípios da autogestão, os quais, ao mesmo tempo em que promovem emancipação e inclusão de indivíduos normalmente excluídos da sociedade e em situação de vulnerabilidade social, contribuem positivamente com o meio ambiente (Fidelis et al., 2015; Silva, 2017; Virgolin et al., 2015).

Conforme Virgolin et al. (2015), é notória a preocupação em relação ao volume excessivo de descarte pós consumo, principalmente quando se tratam de recursos naturais não renováveis utilizados na produção. Em vista disso, uma forma de amenizar tais impactos é oportunizada através da reciclagem. De acordo com Fortuna e Foschiera (2015), o processamento dos resíduos sólidos sob o viés da reciclagem se dá através de algumas fases, sendo a coleta seletiva, triagem e classificação, e comercialização.

Consoante a isso, Silva (2017) destaca enquanto um conjunto de processos em vista da reintrodução de produtos recicláveis, isto é, busca-se transformá-los em insumos produtivos. Dessa 
forma, se trabalha a logística reversa dos produtos, os reutilizando e destinando corretamente, com o propósito de se estruturar um ambiente melhor (Silva, 2017; Souza et al., 2012).

Virgolin et al. (2015) argumentam que a reciclagem de fato se fortaleceu por volta dos anos 90, por meio de diversas ações e políticas que foram desenvolvidas direcionadas a gestão correta dos resíduos. Trindade e Silva (2015) corroboram e mencionam que a globalização e o alto consumo fomentaram o crescimento da produção de resíduos; o que acabou tanto por se tornar um problema ambiental, quanto uma solução, dado que diversas pessoas que estavam fora do mercado de trabalho perceberam tal cenário enquanto uma forma de sustento, ou seja, descobriram o trabalho por meio da reciclagem.

Sobre isso, Virgolin et al. (2015) discorrem que não se trata somente de uma solução ambiental, mas uma possibilidade de gerar trabalho e renda para indivíduos que, em muitos casos, encontram-se em vulnerabilidade social. Portanto, os denominados, neste estudo, de 'recicladores', valorizam algo que não possuía utilidade em uma nova mercadoria; seja de forma individual, ou em associações e cooperativas (Fortuna \& Foschiera, 2015; Trindade \& Silva, 2015).

\subsection{Formas de organização dos recicladores}

O trabalho do reciclador, além de ser diretamente integrado ao que ninguém quer - o lixo -, expõe o mesmo a diversas condições de riscos, bem como o faz sofrer preconceito devido sua fonte de renda; a qual é tanto seu sustento quanto uma forma consciente de contribuir positivamente com o meio ambiente (Camardelo et al., 2015).

Aliado a isso, Camardelo et al. (2015), Bastos e Araújo (2015), Silva (2017) e Virgolin et al. (2015) apontam alguns dos riscos que os recicladores estão expostos, sendo: (i) Químicos, pois pode haver os mais diversos restos de resíduos nas embalagens; (ii) Biológicos, como embalagens contaminadas, seringas e vidros; (iii) Físicos, visto que podem trabalhar em locais com instalações precárias, falta de iluminação e equipamentos, ausência de ventilação, cobertura e goteiras; (iv) Acidentais, porque estão expostos a possibilidade de cortes com vidros, metais, acidentes na prensa e por falta de equipamento de proteção individual; (v) Ergonômicos, devido a postura inadequada no momento de realizar os processos da reciclagem; (vi) Vulnerabilidade Emocional, uma vez que podem desenvolver ansiedade, estresse e depressão.

Ademais, De Melo e De lima (2020) retratam em seu estudo o contexto geral em que tais indivíduos se encontram, confirmando as condições complexas que vivenciam, bem como o recurso monetário irrisório que recebem, o qual é para eles seu sustento. Os autores destacam ainda, que mesmo enfrentando situações difíceis em tal contexto, este configura-se enquanto meio de dignidade, 
sobrevivência e resistência, tornando-se, portanto, uma forma de responder a sociedade que não são mais invisíveis (De Melo \& De Lima, 2020).

Neste cenário, segundo exposto na Política Nacional de Resíduos Sólidos, da Lei 12.305/ANO, o interesse reside em incluir tais indivíduos nas sociedades, retirando-os dos lixos, e fomentando práticas em relação ao ambiente e a economia. Sob esta perspectiva, Corrêa e Xavier (2013, p. 15) argumentam que "em países como o Brasil, as altas taxas de reciclagem na última década refletem principalmente condições sociais e econômicas desfavoráveis de uma parcela significativa da população". Com base no contexto explorado, aponta-se a relevância de que tais indivíduos trabalhem em associações e cooperativas de reciclagem, as quais propiciam que realizem o mesmo trabalho, porém em melhores condições, tanto do trabalho em si, quanto do valor obtido (Silva, 2017; Virgolin et al.2015).

Entretanto, a forma de inserção no trabalho de reciclagem de tais recicladores é inconstante, pois ao passo que participam de uma associação ou cooperativa e percebem que estão lucrando menos, logo voltam a trabalhar individualmente; sofrendo diversos riscos e maior preconceito da população (Silva, 2017). Acerca disso, ressalta-se a relevância do desenvolvimento de políticas públicas mais rigorosas e eficientes, pois assim como Cherfem (2015) e Dagnino e Dagnino (2010) afirmam, existem políticas e programas sociais direcionados a tal causa, o problema que reside é a forma que estão sendo praticados, o que está resultando em pequenas transformações da situação precária que tais recicladores enfrentam diariamente.

\section{Método}

De acordo com Simon (1990), a modelagem de sistemas pode ser classificada em predição ou prescrição. No modelo matemático computacional proposto neste estudo, será utilizada a prescrição com o intuito de promover maior possibilidade de acertos. Utilizou-se como método de pesquisa para o desenvolvimento do modelo computacional a base proposta por Law e Kelton (1991), constituindose das etapas descritas a seguir.

Em um primeiro momento, foi realizada a observação e análise de artigos científicos, dados históricos, manuais de referência e interpretação de dados fornecidos pela associação Recicla, que compõe a etapa de estudos exploratórios; em que houve a estruturação e caracterização do problema, a qual foi composta de elaborar um modelo conceitual, observando quais variáveis melhor delimitam e representam a situação simplificada da realidade (Dresch, Lacerda \& Antunes Júnior, 2015; Morabito \& Pureza, 2010). Dessa forma, a análise dos dados a partir do modelo abrangeu o período de 2009 até 2029, iniciando no ano de planejamento da associação.

Posteriormente, no segundo momento desenvolveram-se soluções através da construção de modelos matemáticos formais capazes de representar o problema, a partir das variáveis que 
caracterizam o problema e da formulação das suas equações matemáticas básicas (Dresch et al., 2015). Na terceira etapa, ocorreu a implementação computacional da solução, utilizando-se o simulador Vensim (Ventana Systems, 2011) da área de System Dynamics. Por fim, na quarta etapa, foram realizados testes para alinhar os resultados obtidos com a realidade observada (Morabito \& Pureza, 2010); verificando a validação do modelo matemático e computacional por meio da simulação experimental de quatro cenários.

Os cenários utilizados para a validação do modelo foram gerados a partir de análises, nas quais foram utilizados dados históricos relativos aos censos populacionais de 2000 e 2010 (Instituto Brasileiro de Geografia E Estatística [IBGE], 2010), o Panorama dos Resíduos Sólidos no Brasil, (Associação Brasileira de empresas de limpeza pública e resíduos especiais [ABRELPE], 2011), e as informações coletadas da associação Recicla. Dessa forma, elaborou-se a formulação da hipótese dinâmica que, segundo Silva (2006), visa observar a teoria do problema a partir de variáveis, as quais incorporam o sistema.

Nesta pesquisa, a hipótese dinâmica converge com três variáveis básicas relacionadas com: a população; a geração de resíduos, e a capacidade operacional da associação Recicla. A primeira variável é pequena, pois o local utilizado para análise cresce a uma taxa de 0,7\% ao ano; dessa forma, mantevese essa taxa de crescimento fixa nos três cenários. A geração de resíduos atual é estimada em 1,296 $\mathrm{kg} /$ pessoa. Salienta-se que o modelo proposto utilizou tais variações na modelagem. Quanto a destinação final dos resíduos, utilizou-se variação nas taxas relacionadas à reciclagem na cidade em que está instalada a Recicla, no Rio Grande do Sul. Tal variação teve por embasamento a dinâmica das taxas médias nacionais, e taxas de tratamento de RSU consideradas adequadas.

Nessa etapa, formula-se uma hipótese que demonstre, o mais próximo da realidade, a dinâmica interna como consequência da estrutura do sistema, através da interação entre as variáveis e os pressupostos representados no modelo (Strauss, 2010). Com base nisso, a hipótese dinâmica de Sistema Dinâmico pode ser desenhada com a associação da variável populacional como geradora de RSU, influenciando diretamente a quantidade total destes. Sendo assim, a quantidade de RSU destinada à reciclagem também está relacionada com a variação populacional.

\section{Desenvolvimento do modelo de simulação}

Em diversas localidades, a separação de RSU destinados para reciclagem é realizada por recicladores organizados tanto informalmente quanto em associações de reciclagem. O modelo proposto abrange as variáveis que compõe o crescimento populacional, alinhando-as a produção de resíduos sólidos por esses indivíduos, disposto a atender localidades específicas, observando a capacidade de reciclagem do centro de reciclagem, tendo em vista a quantidade de pessoas que irá 
atuar no processo de separação e destinação dos resíduos sólidos, bem como as taxas de coleta de cada localidade.

Para a identificação e definição das variáveis componentes do modelo de simulação, conforme a Figura 1, foi utilizado o trabalho desenvolvido por Simonetto e Löbler (2014). A validação foi realizada com a observação do sistema e a conferência de profissionais da área. As variáveis selecionadas, bem como suas inter-relações com outras variáveis, que influenciam nos valores totais de geração e disposição final dos RSU, são as seguintes:

- Taxa de nascimento anual (NascTaxa)

- Taxa de mortalidade anual (MortTaxa)

- Taxa de imigração anual (ImigTaxa)

- Taxa de emigração anual (EmigTaxa)

Figura 1

Modelo de simulação desenvolvido

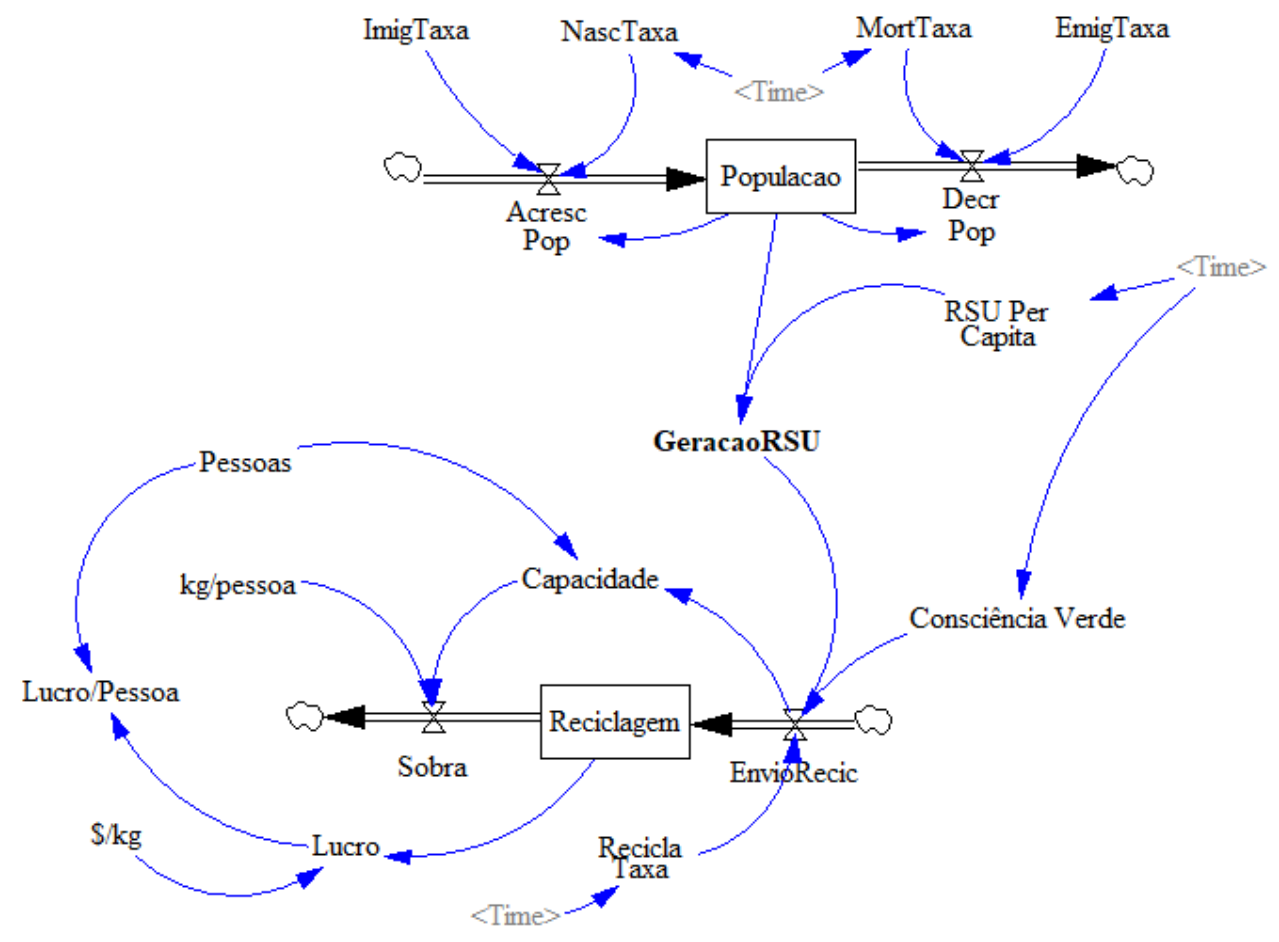

Fonte: Desenvolvido pelas autoras (2019).

Argumenta-se que tais taxas influenciam diretamente os fluxos de entrada e saída populacional (AcrescPop e DecrPop), os quais determinam a população total (Populacao) do município. Em síntese, foi utilizado no modelo a taxa de crescimento natural (total de nascimentos menos o total de mortes), 
a qual corresponde à forma de crescimento ou redução da população local e que, em áreas específicas, é necessário considerar também as migrações. Essas variáveis são representadas pelas Equações 1, 2 e 3 na formulação matemática do modelo de equações.

A quantidade média de resíduos (RSUPerCapita) gerada por cada habitante multiplicada pela população total do município resulta na quantidade total de resíduos (GeracaoRSU) do município. As variáveis descritas são representadas na Equação 4 do modelo matemático. A taxa percentual absorvida pela reciclagem do município (ReciclaTaxa) dependente da quantidade estimada que é retida para reciclagem, não sendo consideradas todas as outras taxas de destinação de RSU; como aterro sanitário, incineração, descarte inadequado, entre outras. Essa taxa também pode ser visualizada nas equações da formulação do modelo matemático, assim como o fluxo de entrada de resíduos na associação para reciclagem, o qual representa a totalidade anual de RSU destinado para esse fim, obtido através do produto da quantidade total de resíduos pela taxa percentual.

Desta forma, a formulação do modelo matemático é a seguinte:

(2) $\quad \operatorname{AcrescPop}(t)=($ Populacao $(t) * \operatorname{ImigTaxa})+($ Populacao $(t) *$ NascTaxa $)$

(3) $\quad$ DecrePop $(t)=($ Populacao $(t) *$ EmigTaxa $)+($ Populacao $(t) *$ MortTaxa $)$

(4) GeracaoRSU $=$ RSU Per Capita $*$ Populacao $* 365$

(5) $\quad$ EnvioRecic $=$ GeracaoRSU $*$ ReciclaTaxa $(t) *$ Consciencia Verde

(6) Reciclagem $=$ EnvioRecic - Sobra

(7) $\quad$ Capacidade $=$ EnvioRecic/Pessoas

(8) $\quad$ Sobra $=$ Capacidade $-" k g / p e s s o a "$.

Finalmente, a equação que representa as variáveis relativas aos fluxos de entrada (EnvioRecic) está descrita no modelo matemático na Equação 5. A capacidade operacional em função da quantidade de pessoas, Equação 7, além da sobra de materiais, que é função da capacidade menos o máximo estimado que cada reciclador consegue separar por ano (Equação 8); e a reciclagem que trata do fluxo do resíduo em relação ao que sobrou do processo, também podem ser visualizados na formulação do modelo matemático. O valor para a variável "kg/pessoa", que compõe a equação 8, dependerá da média que cada reciclador consegue reciclar em cada centro de reciclagem específico.

Com isso, tem-se o modelo com as equações matemáticas que viabiliza a prescrição dos cenários futuros, possibilitando promover maior nível de acertos. Na sequência, será realizada a observação do modelo a partir dos dados coletados na associação Recicla. 


\section{Análise de cenários a partir do modelo de simulação}

Na cidade em que está instalada a associação Recicla, a qual possui uma população de cerca de 62.776, segundo o censo populacional de 2010 (IBGE, 2010), há outras associações de recicladores. A experimentação do modelo, em que se utilizou para simulação dados reais e as taxas da cidade em que está localizada a Recicla, testou as hipóteses para oito e sessenta e quatro recicladores realizando a separação dos RSU. Essas informações foram cruzadas com as possibilidades da situação atual, ou seja, sem campanha de reciclagem e com campanha para o fomento e conscientização da necessidade de separação e reciclagem de RSU no município. A partir disso, obteve-se um quadro contendo desde o melhor cenário, com 64 recicladores e com campanha, e o pior cenário, com 8 recicladores e sem campanha, em que se gerou quatro cenários, conforme exposto na Figura 2. Salienta-se que a legenda dos cenários foi obtida a partir do software Vensim.

Figura 2

Especificação dos cenários validados pelo modelo

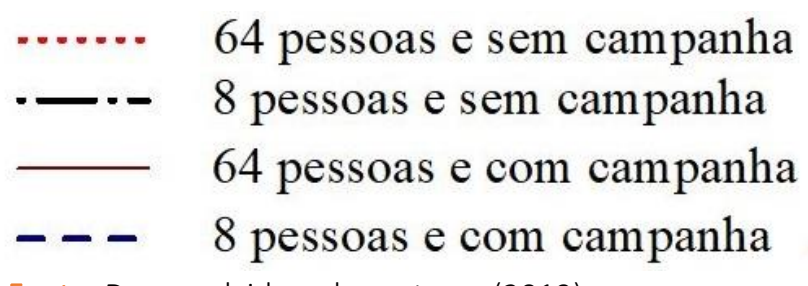

Fonte: Desenvolvido pelas autoras (2019).

Após a definição dos cenários para a realização do experimento utilizando o modelo, foram executadas as simulações. O horizonte de tempo simulado se refere ao período de 2009 a 2029, já que a associação Recicla foi construída a partir de 2009, e determinou-se um período de vinte anos para análise dos dados, tendo como visualização os dados dos últimos dez anos, para avaliação do modelo e do próximo decênio como prescrição.

Quanto a análise dos dados percebe-se, conforme a Figura 3, a curva de aumento da reciclagem ao longo dos vinte anos. No entanto, a curva não varia significativamente com o aumento de recicladores. De cima para baixo, observa-se que quanto mais recicladores, menor é o aumento da reciclagem; já que com mais de trinta e dois recicladores a quantidade de RSU diminui significativamente. Com isso, evidencia-se que o número ideal de recicladores para essa comunidade, com a quantidade de resíduos coletados atualmente, ainda que com uma campanha de reciclagem estimulando a coleta seletiva em 8\%, seria em torno de dezesseis pessoas. 
Destaca-se ainda, que a linha marrom contínua superior na Figura 3 se refere a sessenta e quatro recicladores e possui ação de campanha. No centro do gráfico estão a linha vermelha e pontilhada, que se refere a sessenta e quatro pessoas e sem campanha e oito pessoas e com campanha e bem a baixo no gráfico, oito pessoas e sem campanha, conforme a linha preta com traço e ponto. Diante disso, é possível verificar que quanto maior o número de pessoas trabalhando, o que está correlacionado com o fato de haver campanha, maior é a reciclagem ao longo do tempo, e que mais pessoas trabalhando aumentam exponencialmente a capacidade de reciclagem.

Evidenciou-se que o cenário de oito recicladores com campanha possui reciclagem inferior ao comparativo com o de dezesseis recicladores sem a campanha até 2025. Contudo, com a ação da campanha haverá uma elevação dessa variável, que se mantém crescente a partir de 2026. Além disso, o menor cenário de reciclagem, distante dos demais, é o de oito pessoas sem campanha. Com isso, os cenários são crescentes quando ocorre campanha, já que há mais resíduos sólidos disponíveis para a reciclagem. Entretanto, a inclinação é relativamente sem impacto entre os cenários de sessenta e quatro recicladores com ou sem campanha, havendo a necessidade de ampliar a campanha significativamente para que haja um efeito vantajoso.

\section{Figura 3}

Predição de reciclagem para os próximos 10 anos

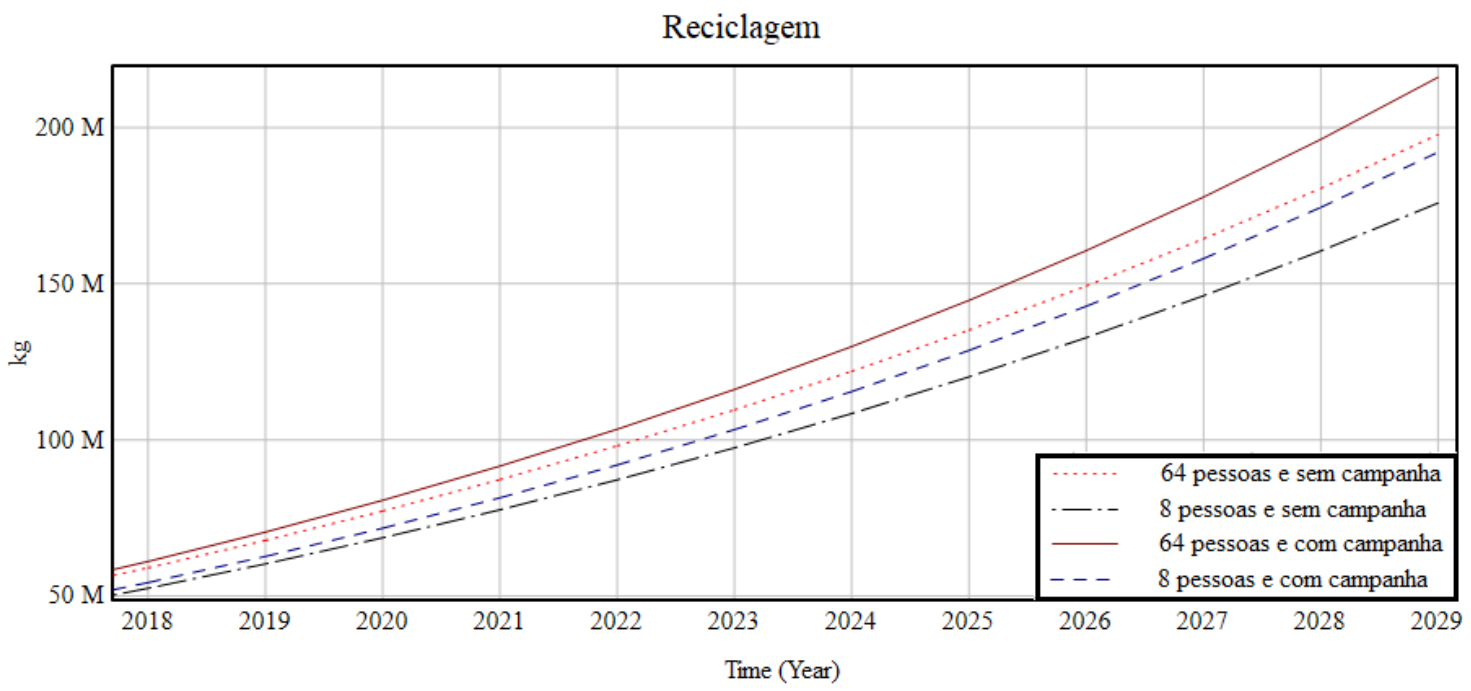

Fonte: Desenvolvido pelas autoras (2019).

Em relação a variável relativa à quantidade de sobra de RSU, que não foi reciclado durante o processo de reciclagem, conforme visualiza-se na Figura 4, quanto menos recicladores estão trabalhando, mais resíduos sólidos sobram do processo, o que é coerente com a situação. As duas linhas com maior sobra de material, oito recicladores com campanha, representam o pior cenário para sobra 
de resíduos, já que são poucas pessoas trabalhando e mais coleta. Semelhante ocorre quando oito pessoas estão trabalhando e não há campanha, ou seja, também há disponibilidade de poucos trabalhadores, com isso, sobra RSU que foi coletado e não foi reciclado.

Quando se observa no gráfico sessenta e quatro pessoas, nas situações com e sem campanha, verifica-se que esses cenários possuem tendência para que não sobre RSU, pois as linhas possuem variação baixa na inclinação da curva ao longo do tempo, já que a sobra de RSU não cresce significativamente. Caso fossem testados cenários com mais trabalhadores, a tendência seria se aproximar de zero a sobra de material por reciclar.

\section{Figura 4}

Resíduos sólidos que sobram do processo de reciclagem

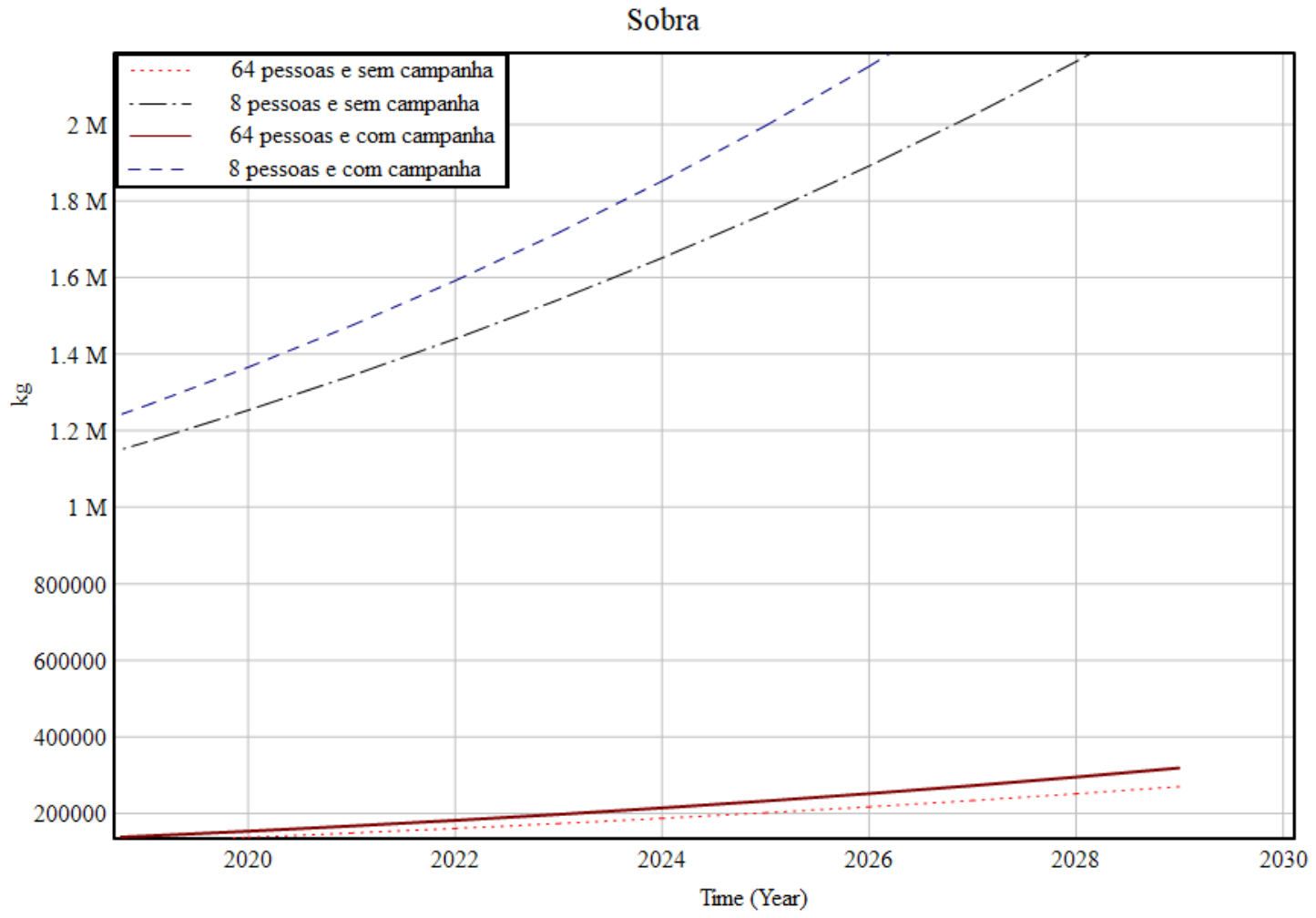

Fonte: Desenvolvido pelas autoras (2019).

Já no que tange a variável lucro, observa-se na Figura 5 que quanto mais colaboradores e campanha, maior será o lucro total da associação. O lucro aqui aparece como o valor necessário para o retorno ao reciclador, pois ainda que seja uma associação que não visa lucros, o envolvido atua nesse sistema com o objetivo de sua sustentabilidade. Dessa forma, essa variável foi utilizada para que seja estimado o retorno do benefício monetário para cada indivíduo.

O que se percebe, no entanto, é que a proporção vai diminuindo quanto mais recicladores a Recicla tem trabalhando, pois o retorno individual será menor do que se houver menos indivíduos. Com 
sessenta e quatro recicladores e com campanha, tem-se o melhor cenário de lucro para a associação, ou seja, é o maior; enquanto o pior cenário é oito sem campanha.

Desta forma, o lucro vai sendo ampliado quanto mais recicladores e maior impulso de campanha está disponível. Visto isso, oito recicladores e sem campanha é o menor lucro, oito recicladores e com campanha cresce um pouco, assim como sessenta e quatro recicladores sem campanha; porém o maior lucro é com sessenta e quatro recicladores e com campanha de fomento.

\section{Figura 5}

Lucro total da associação Recicla

\section{Lucro}

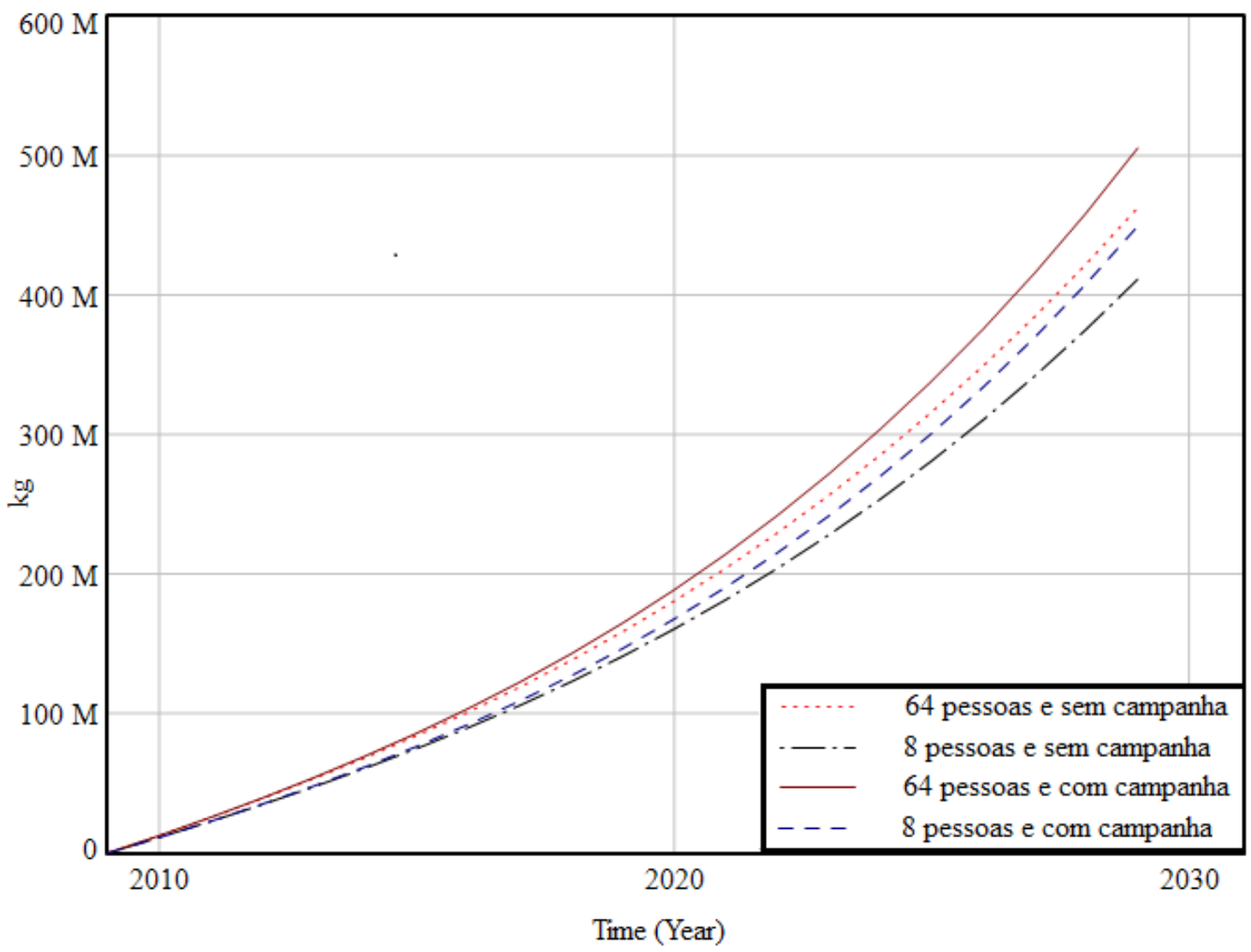

Fonte: Desenvolvido pelas autoras (2019).

Em contrapartida, na Figura 6, para a variável lucro por reciclador os melhores cenários são invertidos. Neste sentido, quanto mais recicladores tem-se, menos RSU disponíveis para cada um. O melhor cenário é o que dispõe menos recicladores, sendo os oito atuais e havendo campanha. O segundo melhor cenário é o de oito, sem campanha. Os piores cenários para o lucro por reciclador são os que possuem mais recicladores disponíveis, ou seja, sessenta e quatro com campanha e sessenta e quatro sem campanha. 
Com isso, evidenciou-se que para o lucro total da associação, quanto mais pessoas estiverem trabalhando e maior campanha de coleta houver, melhores serão os cenários. Já em relação ao lucro individual, deve haver um equilíbrio, pois para que seja distribuído por reciclador, é necessária uma campanha massiva. Neste sentido, é possível verificar que o sistema de gestão deve equilibrar a quantidade de recicladores em relação ao que a Recicla absorve de RSU, a fim de não desmotivar, nem prejudicar economicamente os recicladores.

\section{Figura 6}

Lucro total por reciclador

\section{Lucro/Pessoa}

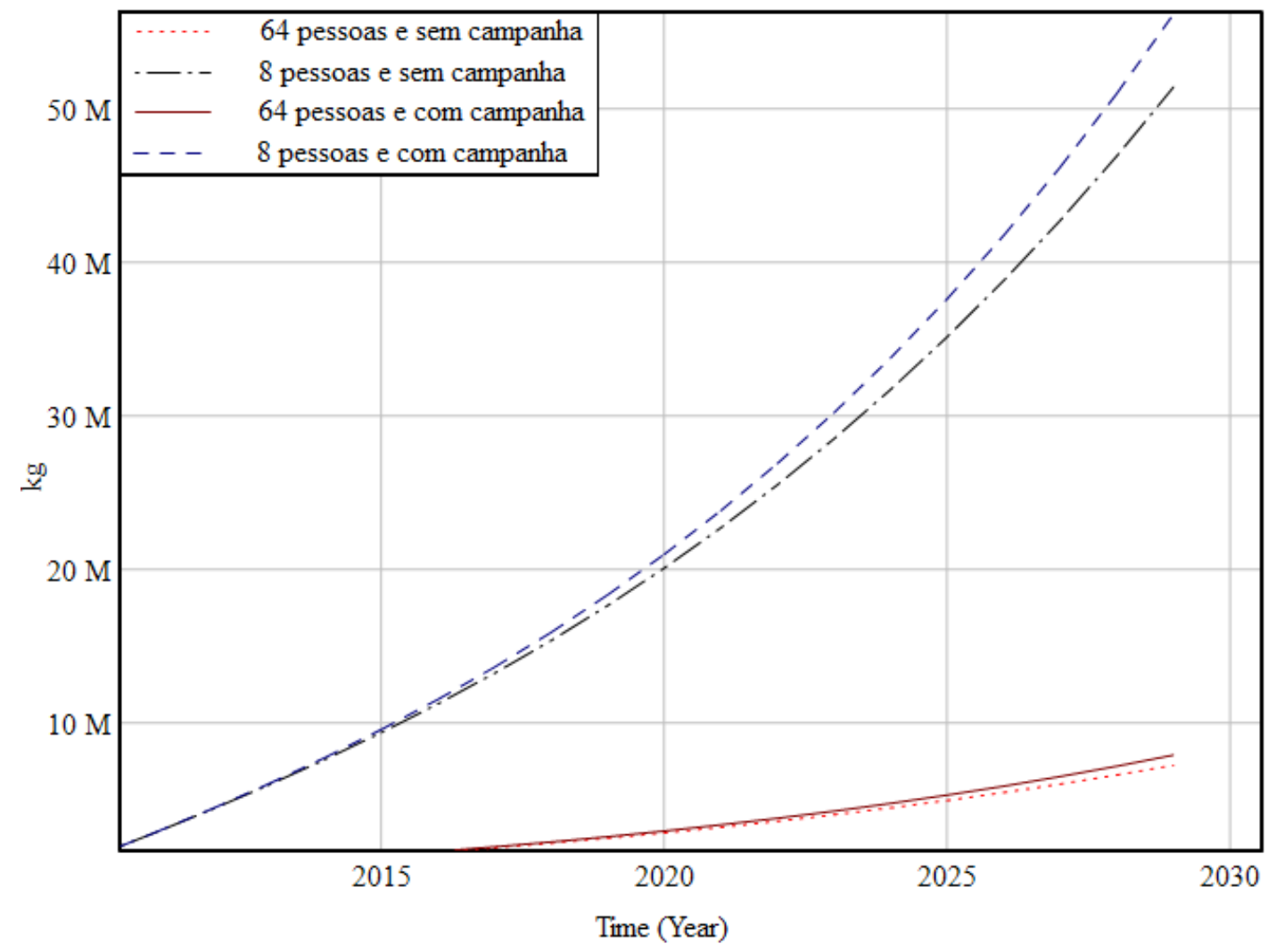

Fonte: Desenvolvido pelas autoras (2019).

Com isso, é possível observar que os cenários corroboram com as dados apresentados anteriormente, uma vez que, com campanhas massivas junto à comunidade é possível contribuir para a diminuição do impacto ao meio ambiente em função da ampliação da destinação correta dos RSU; bem como avaliar a capacidade da Recicla em coletar, separar e destinar corretamente o material recebido, podendo ser melhor distribuído.

Tal constatação corrobora com Tiew et al. (2019), pois assim como defendido pelo autor, um espaço de reciclagem vai realmente conseguir crescer caso haja a conscientização da comunidade em 
destinar corretamente os resíduos. Todavia, tal contexto está diretamente atrelado, também, as políticas públicas, as quais precisam direcionar maiores esforços a tais causas.

No mesmo sentido, Cherfem (2015) e Dagnino e Dagnino (2010) apontam sobre a relevância de políticas públicas que impulsionem maior atenção a esta classe de trabalhadores e sua forma de organização, bem como atentem a comunidade como um todo sobre o papel que devem cumprir enquanto seres que pertencem a uma sociedade. Assim, tanto os recicladores, quanto os agentes públicos e a comunidade em geral devem esforçar-se para que haja maior crescimento, o que resultará positivamente a todos.

Caso haja mudança em tal contexto, a Recicla pode passar a ter maior autonomia frente a sua estabilidade, conforme discutido anteriormente, através da literatura observada (Fidelis et al., 2015; Silva, 2017; Virgolin et al., 2015); refletindo imediatamente sobre o meio ambiente, a sociedade, a coletividade e cada indivíduo envolvido no processo.

A partir dos resultados, foi possível observar o comportamento do modelo, que se mostrou atendendo as expectativas. O modelo foi analisado por profissionais da área que confirmam sua validade, bem como contribuição para a discussão da campanha de RSU e da otimização da distribuição de recicladores por centros de reciclagem. Além disso, ele facilita a observação de quais são os melhores índices de campanha para o benefício das pessoas que trabalham com a reciclagem.

\section{Considerações finais}

Este artigo teve como objetivo desenvolver e avaliar um modelo de simulação computacional na associação Recicla. Com base nos cenários analisados, percebeu-se o grande impacto que possui a campanha, dado que, quanto maior for a mesma, maior será o lucro total, bem como por reciclador, havendo maior desenvolvimento da associação Recicla como um todo.

Ao simular o modelo de 2009 a 2019, pode-se alinhar o histórico dos dados passados com o modelo e verificar sua validade e, com isso, formular o que ocorrerá nos próximos dez anos. O modelo também verifica o incremento da população e o alargamento da produção de RSU. Dessa forma, verificam-se curvas ascendentes para a maioria das simulações.

Salienta-se que os cenários produzidos pelo modelo confirmam informações sobre o aumento de reciclagem quanto maior for a campanha e a quantidade de recicladores, também confirmam as atribuições de que quanto mais recicladores, menos RSU sobram do processo. Além disso, destaca-se a possibilidade de visualização dos cenários, a qual contribui para que sejam verificados a quantidade de recicladores ideal para cada arrecadação, bem como aponta que o aumento da mesma possibilita maior envolvimento de recicladores e maior lucro individual, definindo o ponto de equilíbrio entre coleta e pessoas. 
Logo, com base nos cenários analisados no estudo, acredita-se que enquanto não há políticas públicas efetivas e apoio da comunidade na destinação dos resíduos, ainda se torna pertinente que os reciclados recolham seus materiais fora da associação, para que assim consigam obter maior lucro. Entretanto, com base na literatura defendida, tal situação gera ainda mais riscos a tais indivíduos, o que se torna um impasse entre conseguir se sustentar de uma melhor forma, ou se manter seguro. Em vista disso, ressalta-se que, tratando de uma associação de reciclagem advinda da economia solidária, o ideal seria seguir atuando na associação, pois parte-se do princípio da coletividade.

Enquanto implicação gerencial, o estudo contribui em oferecer um panorama da situação atual e futura da Recicla, o qual pode ser utilizado enquanto base para planejamento da própria associação, bem como de entidades públicas, a fim de criar meios para modificar tal cenário; dado que, infelizmente, o mesmo demonstra que para haver maior lucro deve existir um baixo número de recicladores.

O modelo pode ser replicado em outras comunidades e associações, posto que, é possível alterar as constantes e os dados de input para novos outputs de informações, possibilitando a tomada de decisão efetiva do ponto de equilíbrio em que haja favorecimento individual em função do lucro. Existe também, a possibilidade de inserção social dos indivíduos, já que as associações oportunizam o trabalho coletivo, em um ambiente mais saudável, social e digno.

Ademais, há um engajamento ambiental da comunidade, uma vez que, quanto maior for a participação de toda a população na coleta seletiva, maior será reutilização e o descarte correto e, portanto, o bem estar ambiental e social. Aponta-se isso, pois haverá menos RSU jogado no meio ambiente e a reciclagem permite o reuso de matéria prima, evitando que novas matérias primas sejam removidas do meio ambiente, também proporcionando maior saúde para a comunidade que faz parte desse processo.

O modelo matemático computacional possui algumas limitações, uma vez que foi dimensionado dividindo a quantidade de resíduos sólidos disponíveis por cada pessoa, supondo que toda a matéria prima recebida será processada. Dessa forma, desconsiderou-se a quantidade de horas diárias trabalhadas, ou seja, há a possibilidade de que as pessoas trabalhem diferentes quantidades de horas por dia, o que não está sendo calculado pela formulação matemática. Do mesmo modo, poderá haver pessoas com maior habilidade e portando maior produtividade que outras, o que não foi incorporado ao cálculo do modelo computacional. Outra limitação é a possibilidade de que parte do resíduo sólido coletado e selecionado, seja descartado por algum motivo específico depois do processo de reciclagem, dado que o modelo computacional foi programado para gerar resultado positivo de tudo que foi reciclado.

Para estudos futuros, a possibilidade reside em separar os resíduos sólidos por categorias, e testar mais cenários para a disponibilidade de um número maior de recicladores e campanhas massivas. 
Também é possível que o modelo se torne mais robusto para a tomada de decisão, sendo capaz de identificar as fontes de coleta, como residencial, industrial, hospitalar. Destaca-se ainda, o destino da sobra do resíduo, porque pode ser enviado para outras cooperativas, ou distribuído para outras pessoas; além de variáveis diferentes que analisam desperdícios de recursos ou observam outros fatores relacionados com a lucratividade. Por fim, podem ser adotados métodos de análise de capacidade, como o clima, o tipo de resíduo sólido processado, o período do ano e a interação dos recicladores, já que no modelo foi utilizado um valor constante calculado a partir dos dados disponibilizados pela Recicla.

\section{Referências}

Associação Brasileira de empresas de limpeza pública e resíduos especiais. (2011). Panorama dos Resíduos Sólidos no Brasil-2010. Abrelpe. Disponível em: https://abrelpe.org.br/downloadpanorama-2011/

Bastos, H. M., \& Araújo, G. C. (2015). Cidadania, empreendedorismo social e economia solidária no contexto dos catadores cooperados de materiais recicláveis. Revista Capital CientíficoEletrônica, 13(4), 62-79. https://doi.org/10.5935/2177-4153.20150031

Benini, É. A., \& Benini, E. G. (2015). A construção do trabalho associado sob a hegemonia estatal: organização, solidariedade e sociabilidade. Organizações \& Sociedade, 22(74), 325-344. https://doi.org/10.1590/1984-9230742

Borges, T. P., \& De Souza, M. T. C. C. (2020). Psicologia moral e economia solidária: relações teóricas. Revista Organizações \& Sociedade, 27(94), 459-483. https://doi.org/10.1590/1984-9270944

Brasil. (2010). Lei no 12.305, de Agosto de 2010. Institui a Política Nacional de Resíduos Sólidos; altera a Lei no 9.605, de 12 de fevereiro de 1998; e dá outras providências. Brasília. Disponível em: http://www.planalto.gov.br/ccivil_03/_ato2007-2010/2010/lei/l12305.htm

Camardelo, A. M. P., Oliveira, M., \& Stedile, N. L. R. Condições de vida e de trabalho de catadores de resíduos sólidos urbanos na cidade de Caxias do Sul/RS. In: Silva, E. M. T.; Virgolin, I. W. C., \& Camargo, M. A. S. (Orgs.). (2015). Profissão Catador: Alternativas coletivas na geração de trabalho e renda. Curitiba: CRV.

Cherfem, C. O. (2015). A coleta seletiva e as contradições para a inclusão de catadoras e catadores de materiais recicláveis: construção de indicadores sociais. Mercado de trabalho, 59, 89-98. Disponível em: http://repositorio.ipea.gov.br/bitstream/11058/5010/10/bmt_59_economiasolidaria-1.pdf

Coelho, A. P. F., Beck, C. L. C., Da Silva, R. M., Prestes, F. C., Camponogara, S., \& Peserico, (2017). A. Satisfaction and dissatisfaction in the work of recyclable solid waste segregators: convergentcare research. Revista brasileira de enfermagem, 70(2), 384-391.

http://dx.doi.org/10.1590/0034-7167-2016-0325 
Corrêa, H. L., \& Xavier, L. H. (2013). Concepts, design and implementation of Reverse Logistics Systems for sustainable supply chains in Brazil. JOSCM: Journal of Operations and Supply Chain Management, 6(1), 1-25. http://dx.doi.org/10.12660/joscmv6n1p1-25

Daellenbach, H. G., \& Mcnickle, D. C. (2005). Decision making through systems thinking. Palgrave Macmillan.

Dagnino, R. S., \& Dagnino, R. P. (2011). Políticas para inclusão social de catadores de materiais recicláveis. Revista Pegada Eletrônica, especial: o trabalho no lixo, 66-93. Disponível em: https://www.researchgate.net/publication/233381857_Politicas_para_inclusao_social_de_cat adores_de_materiais_reciclaveis

De Melo, E. H. S. R., \& De Lima, C. M. D. (2020). O Papel das cooperativas dos catadores e a parceria com o poder público: estudo de caso na Cooperativa de Recicladores de Lixo Urbano de Maceió-COOPLUM. Diversitas Journal, 5(1), 639-647. https://doi.org/10.17648/diversitasjournal-v5i1-1025

Dresh, A., Lacerda, P., \& Antunes Júnior, J. A. V. (2015). Design Science Research: Método de Pesquisa para avanço da ciência e tecnologia. Porto Alegre: Bookman.

Fidelis, R., Ferreira, M. A., \& Colmenero, J. C. (2015). Selecting a location to install a plastic processing center: Network of recycling cooperatives. Resources, Conservation and Recycling, 103, 1-8. https://doi.org/10.1016/j.resconrec.2015.07.002

Fortuna, V., \& Foschiera, E. M. O catador e a reciclagem: uma alternativa coletiva de trabalho e renda. In: Silva, E. M. T.; Virgolin, I. W. C., \& Camargo, M. A. S. (orgs.). (2015). Profissão Catador: Alternativas coletivas na geração de trabalho e renda. Curitiba: CRV.

França-Filho, G.C. (2007). Teoria e prática em economia solidária: problemática, desafios e vocação. Revista de Ciências Sociais, 7(1), 155-174. https://doi.org/10.15448/19847289.2007.1.2041

Instituto Brasileiro de Geografia E Estatística. (2010). Censo Demográfico 2010. IBGE. Disponível em: http://www.ibge.gov.br/home/download/estatistica.shtm. Acesso em: 11.07.2019.

Law, A. M., \& Kelton, W. D. (1991). Simulation Modeling \& Analysis. 2ed. McGraw-Hill.

Morabito, R., \& Pureza, V. (2010). Modelagem e Simulação. In P. A. C. Miguel (Coord.). Metodologia de pesquisa em engenharia de produção e gestão de operações (pp. 165-194). Rio de Janeiro: Elsevier.

Silva, E. C. P. (2006). O impacto da gestão do tamanho da força policial na taxa de violência em Curitiba: uma abordagem qualitativa sob o referencial da dinâmica de sistemas. 2006. Dissertação (Mestrado em Engenharia de Produção e Sistemas) - Pontifícia Universidade Católica do Paraná, Curitiba.

Silva, S. P. (2017). A Organização Coletiva de Catadores de Material Reciclável no Brasil: dilemas e potencialidades sob a ótica da economia solidária. Texto para discussão n.2268.

Rio de Janeiro: Ipea. Disponível em:

https://www.ipea.gov.br/portal/index.php?option=com_content\&view=article\&id=29271 
Simon, H. A. (1990). Prediction and prescription in systems modeling. Operations Research, 38(1), 714. https://doi.org/10.1287/opre.38.1.7

Simonetto, E. O., \& Löbler, M. L. (2014). Simulação baseada em System Dynamics para avaliação de cenários sobre geração e disposição de resíduos sólidos urbanos. Production, 24(1), 212-224. https://doi.org/10.1590/S0103-65132014000100017

Souza, A. L. A., Sauer, L, \& Benini, E. G. (2019). O processo de institucionalização da economia solidária em Mato Grosso do Sul. Desafio Online, 7(1), 142-178. Disponível em: https://desafioonline.ufms.br/index.php/deson/article/view/2993/5607

Souza, M. T. S., Paula, M. B., \& De Souza-Pinto, H. (2012). O papel das cooperativas de reciclagem nos canais reversos pós-consumo. Revista de Administração de Empresas, 52(2), 246-262. https://doi.org/10.1590/S0034-75902012000200010

Strauss, L. M. (2010). Um modelo em dinâmica de sistemas para o ensino superior. 2010. Dissertação (Mestrado em Administração) - Universidade Federal do Rio Grande do Sul, Porto Alegre.

Tiew, K., Basri, N. E. A., Deng, H., Watanabe, K., Zain, S.M., \& Wang, S. (2109). Comparative study on recycling behaviours between regular recyclers and non regular recyclers in Malaysia. Journal of environmental management, 237, 255-263. https://doi.org/10.1016/j.jenvman.2019.02.033

Torres, A.E., De Carvalho, A.M.R., De Araujo, B.B., \& Rocha, S.R.C. Circular a palavra e construir sentidos: uma experiência de círculo de cultura com catadores de materiais recicláveis. In: Silva, E. M. T.; Virgolin, I. W. C., \& Camargo, M. A. S. (orgs.). (2015). Profissão Catador: Alternativas coletivas na geração de trabalho e renda. Curitiba: CRV.

Trindade, C.R., \& Silva, V.L.L. Coletar, separar e reciclar, um outro olhar para o universo dos catadores. In: Silva, E. M. T.; Virgolin, I. W. C., \& Camargo, M. A. S. (orgs.). (2015). Profissão Catador: Alternativas coletivas na geração de trabalho e renda. Curitiba: CRV.

Unisol. (2017). Aprovado o PL da Economia Solidária. Disponível em: http://www.unisolbrasil.org.br/aprovado-o-pl-da-economia-solidaria/. Acesso em: 11.07.2019.

Ventana Systems. Vensim Simulation Software. Disponível em: http://www.vensim.com. Acesso em: 07.06.2019.

Virgolin, I.W.C., Silva, E.M.T, \& Araújo, R. Relato da experiência do Projeto Profissão Catador: A organização social e econômica de catadores de materiais recicláveis no município de Cruz Alta/RS. In: Silva, E. M. T.; Virgolin, I. W. C., \& Camargo, M. A. S. (orgs.). (2015). Profissão Catador: Alternativas coletivas na geração de trabalho e renda. Curitiba: CRV. 